Original Research Article

\title{
Pharmacoeconomics of desflurane based minimal flow anesthesia for different durations of surgery
}

\author{
Habib M. R. Karim*, Mohd Yunus, Laltanpuii Sailo, Stevie J. N. Sangma, Newstar Syiemiong
}

Department of Anaesthesiology, Critical Care and Pain Medicine, North Eastern Indira Gandhi Regional Institute of Health and Medical Science, Shillong, Meghalaya, India

Received: 28 August 2016 Accepted: 28 September 2016

*Correspondence to:

Dr. Habib M. R. Karim,

Email: drhabibkarim@ gmail.com

Copyright: () the author(s), publisher and licensee Medip Academy. This is an openaccess article distributed under the terms of the Creative Commons Attribution NonCommercial License, which permits unrestricted noncommercial use, distribution, and reproduction in any medium, provided the original work is properly cited

\begin{abstract}
Background: Desflurane is relatively newer volatile anesthetic in clinical practice with many advantages. Unfortunately, it is comparatively costlier. The present observational study is aimed to evaluate the consumption pattern and cost of Desflurane based minimal flow anesthesia with regards to different durations of anesthesia.

Methods: Twenty adults of American Society of Anesthesiologists' class I and II of either sex were enrolled for the study with informed consent during November 2015 to January 2016. Anesthesia was performed using Intermed Penlon sigma Alfa Desflurane vaporizer and Penlon Prima SP2 workstation. Age and opioid compensated minimum alveolar concentration was fixed for each patient and was monitored using Penlon SP M8 monitor and its attached anesthesia gas monitoring system. Bispectral index was used in affordable patients to monitor depth of anesthesia. Data of Desflurane consumption was collected from the digital numerical display on the vaporizer screen. Statistical analysis was done using INSTAT software and cost was calculated from maximum retail price.

Results: Data from 20 patients consisting $60 \%$ male (mean + standard deviation age of $39.8+16.9$ years and weight of $59.7+12.52$ kilograms) were analyzed. Gender had no effect on consumption of Desflurane. Older patients ( $>60$ years) consumed less than the younger $(\mathrm{p}<0.05)$. Mean Desflurane consumption was highest during first 5 minute $(6.2 \mathrm{ml})$ and followed decreasing trend till 45 minute of anesthesia $(\mathrm{p}<0.05)$ followed by a near steady consumption. Cost of Desflurane reduced from Indian Rupees 22/minute for 15 minute anesthesia to Indian Rupees 6/minutes for 3 hours anesthesia.

Conclusions: Desflurane consumption and cost do not depend on sex but on age, flow and time. It becomes more cost-effective for relatively longer duration of minimal flow anesthesia.
\end{abstract}

Keywords: Cost pharmacotherapy, Desflurane consumption, Minimal flow desflurane anesthesia, Pharmacoeconomics

\section{INTRODUCTION}

Health is a basic human need but unfortunately it has become an unaffordable commodity for many. Excessive health care cost is a major concern worldwide. People of developing countries suffer the most as the per capita public expenditure for health is very minimal. On the other hand, along with the provision of quality health care, a reduction in costs through careful management of resources is one of the aims of patients, health insurers and regulatory agencies, including the governmental agencies. Many a times, the cost of advanced, newer drugs and technologies stand as a barrier in the path of delivering top-quality healthcare.
Anesthesia is an integral part of perioperative care of surgical patients. Most people will have to undergo surgery at some point in their life. Anaesthesiologist is responsible for delivering quality anesthetic care. Desflurane is a relatively newer, third generation inhalational volatile anesthetic agent in clinical practice. Over the last decade of clinical use, it has proved to be safe and offer many advantages like precise control over depth of anesthesia along with a rapid, predictable, and clear-headed recovery with minimal postoperative squeal. ${ }^{1,2}$ However, it is relatively costly which always comes in to the mind of both the anaesthesiologist as well as the administration before using it. Therefore, we designed this pilot study with an objective to know the 
cost and consumption pattern of Desflurane based minimal flow anesthesia (MFA) as well as its relationship with different durations of surgery.

\section{METHODS}

After the approval from Institute Research Board and informed consent from the patients, the present prospective cohort study consisting of single cohort was conducted in a tertiary care teaching institute during November 2015 to January 2016. Patients of American Society of Anesthesiologists (ASA) physical class I and II, of both sexes in the age group of 20 to 80 years undergoing elective surgeries under desflurane based general anesthesia were eligible for the study. Obese patients and patients with anticipated difficult airway or whose intubation took more than one minute were excluded. For homogeneity, anesthesia management was standardized. All patients were given injection Fentanyl 2 $\mathrm{mcg} / \mathrm{Kg}$ body weight approximately 5 minute before intubation. Injection Propofol $2 \mathrm{mg} / \mathrm{kg}$ was used and Desflurane (Baxter Healthcare of Puerto Rico) was started at $4 \%$ with $8 \mathrm{~L} /$ minute of fresh gas flow (FGF) after confirming the ventilation. Injection Vecuronium or Rocuronium was used for muscle relaxation. After intubation, FGF reduced to $2 \mathrm{~L} /$ minute and Desflurane was increased to $6 \%$. After 2 minutes, FGF reduced to 1 $\mathrm{L} /$ minute and Desflurane was increased to $8 \%$. The $8 \%$ dial setting was maintained till the target minimum alveolar concentration (MAC) for the patient attained and then FGF was further reduced to $500 \mathrm{ml} /$ minute. The MAC was kept between 1 to 1.2 times of target (calculated) for the patient and Desflurane dial settings changed as required keeping FGF at 500 - 600 ml/minute constant throughout. Injection Paracetamol or Diclofenac Sodium was used (1gm or $75 \mathrm{mg}$ for adult) and injection Fentanyl $0.5 \mathrm{mcg} / \mathrm{kg}$ was repeated every hourly. Injection Vecuronium $1 \mathrm{mg}$ was used every 20 minutes except in few cases where it was guided by neuromuscular monitoring with TOF Watch SX from Organon (Ireland) Ltd. The cases which were expected to run for more than 3 hours were given injection Rocorunium $10 \mathrm{mcg} / \mathrm{kg} / \mathrm{minute}$ infusion. Minute ventilation was adjusted to keep EtCO2 between 32 to $34 \mathrm{mmHg}$. Intraoperative haemodynamics were targeted at $\pm 20 \%$ from baseline. Desflurane was stopped at the near completion of incision site closure.

Age and Fentanyl dose adjusted target MAC was calculated for each patient. Though the MAC-awareness is $0.5-0.6$ of MAC for patients of age between 20 to 40 years, the MAC requirement was taken as $1 \mathrm{MAC}$ for this age group in the present study to have a margin of safety. For each decade after 40 years, a reduction (compensation) of $6 \%$ in MAC was done (e.g. if age is 60 years, age compensated target MAC is 0.88$).{ }^{3}$ Thereafter, MAC was compensated for Opioid. Injection Fentanyl reduces MAC of volatile anesthetic in dose dependant manner. Study have shown that a single intravenous dose of $3 \mathrm{mcg} / \mathrm{kg}$ injection Fentanyl reduced MAC requirement of Desflurane by $50 \% .{ }^{4}$ As we used $2 \mathrm{mcg} / \mathrm{kg}$ Fentanyl bolus and supplemented every hour over and above non-opioids, we took (assumed) 30\% reduction in MAC value in calculation (e.g. compensated MAC for above 60 year old patient will be $0.88 \times 0.7=0.61$ ). For margin of safety, target MAC was kept at around 1 to 1.2 times of calculated target MAC value (e.g. for the same patient compensated MAC target will be 0.61 to 0.74 ). MAC was continuously monitored by using Penlon SP M8 monitor and its attached anesthesia gas monitoring system. However, if clinically it was judged that, Desflurane concentration needs to be adjusted, it was done for short duration. Depth of anesthesia was also monitored using BIS quatro (Aspect Medical Systems) monitoring in affordable and consented patients. Intermed Penlon sigma Alfa Desflurane vaporizer was used in these cases where amount of consumed Desflurane were displayed digitally in numerical values. Amount of consumed Desflurane was noted initially every 5 minute till 15 minute and thereafter every 15 minute from the digitally displayed numerical values. The maximum retail price (MRP) of Desflurane was collected from printed information on the bottle (INR 8600/240 $\mathrm{ml}$ ). Quantitative data were analysed using unpaired t test and ANOVA with post-test and a p value of $<0.05$ was considered as significant. Ordinal data are expressed in absolute number and percentage scale. Statistical and graphical analysis was performed on INSTAT and Graphpad Prism 5 software (Graphpad software, Inc., La Zolla, CA, USA). Cost per minute was calculated using MRP of Desflurane.

\section{RESULTS}

Data from a total of 20 patients (12 men, 08 women); 13 $(65 \%)$ of ASA I and $7(35 \%)$ of ASA II were studied for this purpose. BIS could be monitored in only two patients along with MAC monitoring which was done in all patients. The mean \pm SD: standard deviation $(95 \%$ confidence interval: $\mathrm{CI})$ age of the patients were $39.8 \pm$ $16.90(31.88-47.71)$ years and weight of $59.7 \pm 12.5 \overline{2}$ $(53.83$ - 65.56) $\mathrm{Kg}$ respectively. Three (15\%) patients were in the above 60 years age group and all of them were of ASA physical class II. The Desflurane consumption was less in these older patients than the younger $(p<0.05)$ (Table 1). However, there was no statistically different consumption among male and female patients (Table 2).

Mean Desflurane consumption for all patients were highest during the first 5 minute $(6.2 \mathrm{ml})$ followed by 2.03 and $0.81 \mathrm{ml}$ for next consecutive 5 minutes respectively and the difference was extremely significant ( $\mathrm{p}<0.0001)$. The consumption pattern followed a decreasing trend till 45 minutes of anesthesia $(p<0.05)$. (Table 3, Figure 1) Thereafter, the consumption of Desflurane remained nearly static with mean consumption of 1.9 to $2 \mathrm{ml} / 15$ minute of anesthesia ( $>0.05$ ). (Table 3, Figure 2) Duration of anesthesia was inversely proportional to the cumulative cost of 
Desflurane consumed. However, after 2 hours of anesthesia cost reduction was of not much. The cumulative amount of Desflurane consumed over the different duration of surgeries and the calculated costs are presented in the Table 4.

Table 1: Demographic parameters and cumulative Desflurane consumption with different durations of anesthesia in patients of older and younger than 60 years tested with unpaired t test.

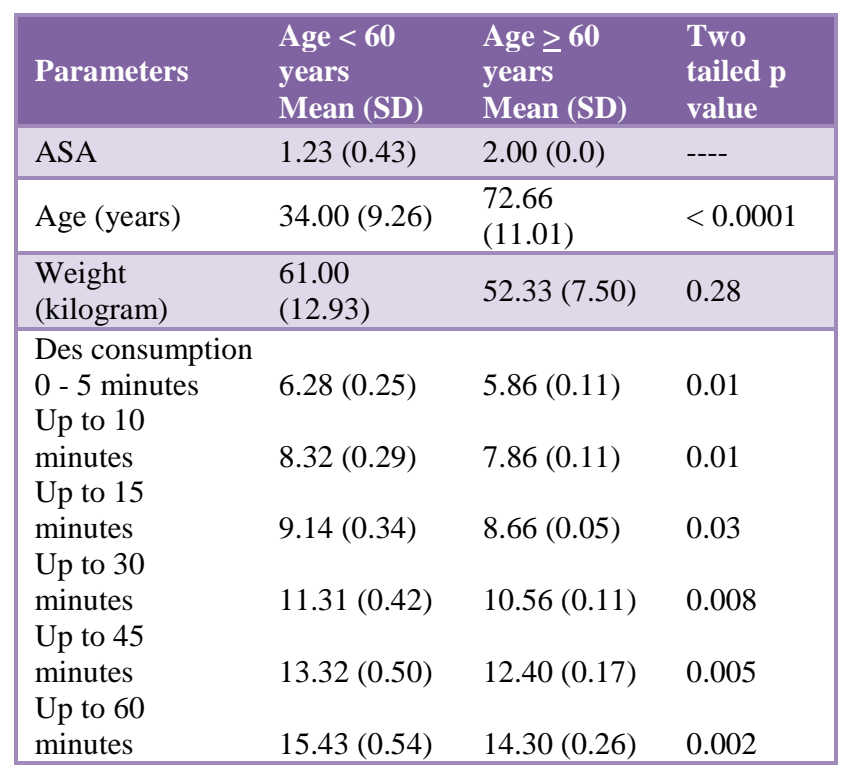

SD - Standard deviation; CI - Confidence interval; ASA American Society of Anaesthesiologists.

Table 2: Demographic parameters and cumulative Desflurane consumption over different durations of anesthesia with sex tested with unpaired $t$ test.

\begin{tabular}{|llll|}
\hline Parameters & $\begin{array}{l}\text { Male } \\
\text { Mean (SD) }\end{array}$ & $\begin{array}{l}\text { Female } \\
\text { Mean (SD) }\end{array}$ & $\begin{array}{l}\text { Two } \\
\text { tailed p } \\
\text { value }\end{array}$ \\
\hline ASA & $1.41(0.51)$ & $1.25(0.46)$ & 0.47 \\
\hline Age (Years) & $\begin{array}{l}37.91 \\
(17.11)\end{array}$ & $42.62(17.32)$ & 0.55 \\
\hline $\begin{array}{l}\text { Weight } \\
\text { (kilograms) }\end{array}$ & $\begin{array}{l}\text { (1.33) } \\
\text { Des consumption }\end{array}$ & $57.25(13.78)$ & 0.49 \\
0 - 5 minutes & $6.3(0.31)$ & $6.1(0.18)$ & 0.12 \\
Up to 10 minutes & $8.35(0.37)$ & $8.11(0.15)$ & 0.10 \\
Up to 15 minutes & $9.15(0.43)$ & $8.93(0.15)$ & 0.18 \\
Up to 30 minutes & $11.33(0.55)$ & $11.00(0.23)$ & 0.12 \\
Up to 45 minutes & $13.37(0.64)$ & $12.91(0.30)$ & 0.07 \\
Up to 60 minutes & $15.44(0.72)$ & $14.94(0.41)$ & 0.11 \\
$\begin{array}{l}\text { Up to 75 minutes } \\
\text { Up to 90 minutes }\end{array}$ & $17.50(0.79)$ & $17.08(0.20)$ & 0.23 \\
$\begin{array}{l}\text { Up to 105 } \\
\text { minutes }\end{array}$ & $21.83(0.78)$ & $19.02(0.25)$ & 0.08 \\
\hline SD - Stand & $21.10(0.20)$ & 0.18 \\
\hline
\end{tabular}

SD - Standard deviation; CI - Confidence interval; ASA American Society of Anaesthesiologists.
Table 3: Changing trend of Desflurane consumption over different durations of anesthesia tested with one way ANOVA with post-test.

\begin{tabular}{|ll|}
\hline Time period & p value \\
\hline Zero -5 minutes & \\
$5-10$ minutes & $<0.0001$ \\
$11-15$ minutes & \\
\hline $5-10$ minutes $\times 3$ & $<0.0001$ \\
$10-15$ minutes $\times 3$ & \\
$16-30$ min & \\
\hline $10-15$ minutes $\times 3$ & $<0.0001$ \\
$16-30$ minutes & \\
$31-45$ minutes & 0.004 \\
\hline $16-30$ minutes & \\
$31-45$ minutes & \\
$46-60$ minutes & \\
\hline $31-45$ minutes & 0.22 \\
$46-60$ minutes & \\
$61-75$ minutes & 0.45 \\
\hline $46-60$ minutes & \\
$61-75$ minutes & \\
$76-90$ minutes & \\
\hline
\end{tabular}

\section{DISCUSSION}

Desflurane, although was prepared in 1960s, it was approved for clinical use only in $1992 .{ }^{5,6}$ Study showed that, there have been a changing pattern of consumption of volatile anesthetics and Desflurane consumption is increasing. ${ }^{7}$ However, this newer drug is costlier too resulting in higher cost for health care delivery. Even in advanced and economically sound countries like USA, the rate of increase in expenditure on health care continues to exceed economic growth at an unsustainable pace. $^{8}$ This has lead to increasing pressure to limit health care costs on health authorities.

One of the major drivers of health care costs is inappropriate utilization of advanced medical technology. ${ }^{8}$ Therefore, to control the health care cost, it has become necessity that the limited healthcare resources be used equitably and judiciously. Healthcare expenditures must be correlated with high quality and efficiency in the delivery of services to improve health outcomes. This requires understanding the benefits and efficacy of clinical procedures, recognizing the major drivers of health care costs, and identifying potential means for increase in savings.

Present study was designed to understand the consumption pattern of Desflurane based minimal fresh gas flow anesthesia for different durations. The intention behind the study was that the finding can be incorporated in to clinical practice to improve cost effectiveness without compromising on quality of care if found suitable. 
Low flow anesthesia cuts cost of volatile anesthetics. Both low flow and minimal flow anesthesia with low soluble agents like Desflurane have shown economic advantage. ${ }^{10}$ However, there is a comparative dearth of data from third world countries on Desflurane consumption and cost for different duration of surgeries. In the present study, it has been tried to quantify the consumption pattern over the different anesthesia duration with minimal flow. This will help anesthesiologists understand the consumption pattern of Desflurane and design their own clinical practices as well as the health authority in preparation of standard operating protocols for Desflurane based minimal flow anesthesia.

Table 4: Cumulative consumption of Desflurane and its cost/minute of anesthesia for different durations tested with unpaired t test. \#derived from only two values.

\begin{tabular}{|c|c|c|c|c|}
\hline $\begin{array}{l}\text { Desflurane } \\
\text { Anesthesia } \\
\text { duration }\end{array}$ & $\begin{array}{l}\text { Cumulative } \\
\text { Consumption } \\
\text { Mean (SD) in } \mathrm{ml}\end{array}$ & $\begin{array}{l}\text { Cumulative } \\
\text { Consumption } \\
95 \% \mathrm{CI} \text { in } \mathrm{ml}\end{array}$ & $\begin{array}{l}\text { Total Cost }(\text { INR })^{\$} \\
\text { Based on } 95 \% \text { CI } \\
\text { (Mean) }\end{array}$ & $\begin{array}{l}\text { Cost / minutes } \\
\text { (INR) Based on } \\
\text { Mean }\end{array}$ \\
\hline 15 minutes & $9.07(0.36)$ & $8.90-9.23$ & $319-331(325)$ & 21.67 \\
\hline 30 minutes & $11.2(0.47)$ & $10.97-11.42$ & $393-409(401)$ & 13.37 \\
\hline 45 minutes & $13.19(0.57)$ & $12.92-13.45$ & $463-482(473)$ & 10.51 \\
\hline 60 minutes & $15.25(0.66)$ & $14.94-15.57$ & $535-558(547)$ & 9.17 \\
\hline 75 minutes & $17.36(0.68)$ & $17.02-17.70$ & $610-634(622)$ & 8.29 \\
\hline 90 minutes & $19.47(0.72)$ & $19.07-19.87$ & $683-712(698)$ & 7.76 \\
\hline 105 minutes & $21.63(0.79)$ & $21.10-22.17$ & $756-795(775)$ & 7.38 \\
\hline 120 minutes & $23.84(0.91)$ & $23.00-24.68$ & $824-884(854)$ & 7.17 \\
\hline 135 minutes & $25.83(1.06)$ & $24.71-26.95$ & $886-966(926)$ & 6.86 \\
\hline 150 minutes & $28.20(1.20)$ & $26.27-30.12$ & $941-1079(1011)$ & 6.74 \\
\hline 165 minutes & $30.43(1.35)$ & $27.06-33.80$ & $970-1211(1090)$ & 6.61 \\
\hline 180 minutes & $32.40(1.38)$ & $28.95-35.84$ & $1037-1284(1161)$ & 6.45 \\
\hline 195 minutes & $34.33(1.35)$ & $30.96-37.70$ & $1109-1351(1230)$ & 6.31 \\
\hline 210 minute & $35.50(0.14)$ & $34.22-36.77$ & $1226-1318(1272)$ & 6.06 \\
\hline
\end{tabular}

\$nearest full digit; SD - Standard deviation CI - Confidence interval; INR - Indian Rupee

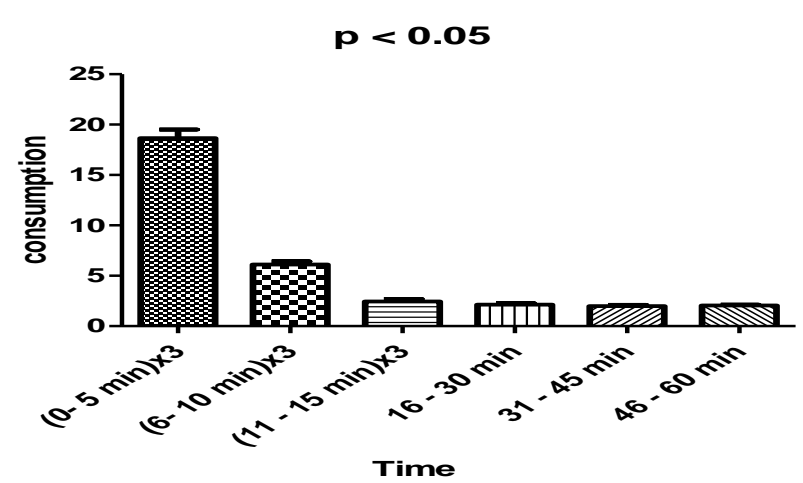

Figure 1: One bar per column graph with mean and standard deviation showing the variation of consumption over time ( 0 minutes to 60 minutes of anesthesia) and its significance.

Volatile anesthetic consumptions are calculated from the fresh gas compositions based formulas usually. Although this technique has shown to be sufficiently accurate, it overestimates consumption by $5-6 \%$ than gold standard pre and post use weight measurements. ${ }^{11}$ In the present study, readings were taken directly from the numerical digital display of vaporizer, which is expected to be near accurate of weight measurement technique.

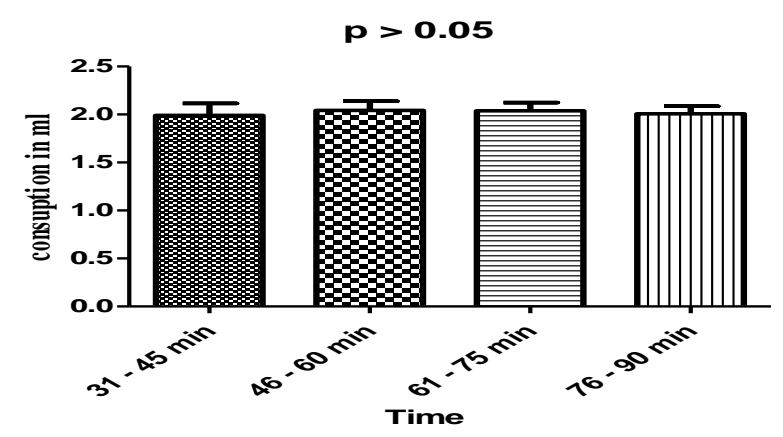

Figure 2: One bar per column graph with mean and standard deviation showing the variation of consumption over time (31 minutes to 90 minutes of anesthesia) and its significance.

The consumption of Desflurane reached near steady state in nearly 45 minute in the present study. As Desflurane metabolism is nearly nil in body and excreted only through lung, this finding indirectly indicates that the partial pressure gradients across the vessel rich and poor 
compartments has become very low or reached a near steady state with the partial pressure of Desflurane in the blood. It is thus supplementing our knowledge on the pharmacokinetics of Desflurane based minimal flow anesthesia in adult.

In this cost analysis study, it was found that the cost of Desflurane per MAC hour was US\$ 5.30 for more than 2 MAC hour duration (which is equivalent to INR 345 taking 1 US $\$=65$ Indian Rupee (INR), approximate market value at the time of wetting this manuscript). ${ }^{12}$ This is on the other hand is equivalent to 5.75 INR/ MAC minute. This finding is nearly same as the findings of the present study after 3 hours of anesthesia (6.31 $\mathrm{INR} /$ minute). However, it is not clear whether; high flow (which is required at the time of induction) was taken into consideration in the calculations of said study. ${ }^{12}$ If we consider Desflurane consumption only at the maintenance phase of anesthesia with minimal flow $(500 \mathrm{ml} / \mathrm{minute}$ as noted in the table of the said study), the consumption of Desflurane per hour comes approximately $8 \mathrm{ml}$ in the present study, which costs INR 4.77 /minutes of anesthesia.

The number of patients monitored by BIS for depth of anesthesia was only 2 (10\%). However, it was observed that the calculated age and Opioid compensated target MAC for both the patients were corresponding to the BIS value of 45 to 54 during maintenance phase of anesthesia. These values are within the range of advocated BIS value of 40 to 60 for general anesthesia. ${ }^{13}$

This indicates that the calculated compensated target MAC in the present study was adequate for serving the purpose of maintaining adequate depth of anesthesia. Clinical trials have also shown that the end tidal anesthetic gas guided anesthesia provides equal safety in terms of awareness as compared to BIS guided anesthesia. ${ }^{14}$ Therefore, although low use of BIS was a limitation, the conclusion arrived at would unlikely had been much different if BIS would have been used in all the patients.

One more limitation of the present study was that compensation for falling temperature was not taken in to account while calculating target MAC. The special vaporizer requirement for the use of Desflurane along with relatively advanced anesthesia machine for delivering minimal flow and agent monitoring was also not taken in to consideration while calculating cost. However, considering the present wide availability of such facilities and requirement of specific vaporizer for each and every volatile agent, these limitations are also less likely to affect the outcome of the study.

\section{CONCLUSION}

The consumption and cost of Desflurane based anesthesia is dependent on fresh gas flow and time but not on sex. It is cost-effective for relatively longer duration of minimal flow anesthesia and the use of Desflurane based anesthesia appears to be feasible even in developing countries. The myth "Desflurane to be used for short duration procedure" needs to be revisited. Considering the postoperative recovery advantages it can be regarded as a suitable inhalational anesthetic agent for quality anesthetic care even in developing countries. Further prospective study will be required to exactly quantify the magnitude of the cost-effectiveness.

\section{Funding: No funding sources}

Conflict of interest: None declared

Ethical approval: The study was approved by the Institutional Ethics Committee

\section{REFERENCES}

1. Kapoor MC, Vakamudi M. Desflurane - Revisited. J Anaesthesiol Clin Pharmacol. 2012;28:92-100.

2. Jakobsson J. Desflurane: a clinical update of a thirdgeneration inhaled anaesthetic. Acta Anaesthesiol Scand. 2012;56:420-32.

3. Eger EI II. Age, minimum alveolar anaesthetic concentration and minimum alveolar anesthetic concentration-awake. Anesth Analg. 2001;93:94753.

4. Sebel PS, Glass PS, Fletcher JE, Murphy MR, Gallagher C, Quill T. Reduction of the MAC of desflurane with fentanyl. Anesthesiology. 1992;76:52-9.

5. Eger EI 2nd. New inhaled anesthetics. Anesthesiology. 1994;80:906-22.

6. E Virginia. Pediatric Focused Safety Update: Suprane (B) (desflurane). U.S. Food and Drug Administration. June 21st, 2010. Available from: http://www.fda.gov/downloads/AdvisoryCommittees/ CommitteesMeetingMaterials/PediatricAdvisoryCom mittee/UCM216308.pdf. Cited on 21 February 2016.

7. Weinberg L, Tay S, Aykanat V, Segal R, Tan CO, Peyton P, McNicol L, Story DA. Changing patterns in volatile anaesthetic agent consumption over seven years in Victorian public hospitals. Anaesth Intensive Care. 2014;42(5):579-83.

8. American College of Physicians. Controlling Health Care Costs While Promoting The Best Possible Health Outcomes. Philadelphia: American College of Physicians; 2009: Policy Monograph. Available from: https://www.acponline.org/acp_policy/policies/ controlling_healthcare_costs_2009.pdf. Cited on 28th March 2016.

9. Nunn G. Low-flow anesthesia. Contin Educ Anaesth Crit Care Pain. 2008;8:1-4.

10. Elmacioglu MA, Goksu S, Hasan Kocoglu H, Oner U. Effects of flow rate on hemodynamic parameters and agent consumption in low-flow desflurane anesthesia: An open-label, prospective study in 90 patients. Curr Ther Res Clin Exp. 2005;66(1):4-12.

11. Biro P, Kneschke O, Theusinger O M. Accuracy of calculated volatile agent consumption from fresh gas 
content. Acta Anaesthesiol Scand. 2015;59(5):61924.

12. Varkey J, Welliver M. Debunking Volatile Anesthetic Cost Myths Between Sevoflurane and Desflurane. Anesthesia E Journal. 2014;1(2). Available from: http://www.anesthesiaejournal.com/ index.php/ aej/article/view/6 [cited on 2nd March 2016].
13. Punjasawadwong $\mathrm{Y}$, Boonjeungmonkol N, Phongchiewboon A. Bispectral index for improving anaesthetic delivery and postoperative recovery. Cochrane Database Syst Rev 2007;4:CD003843CD003843.

14. Avidan MS, Zhang L, Burnside BA, Finkel KJ, Searleman AC, Selvidge JA, et al. Anesthesia awareness and the bispectral index. N Engl J Med. 2008;358:1097-108.

Cite this article as: Karim HMR, Yunus M, Sailo L, Sangma SJN, Syiemiong N. Pharmacoeconomics of desflurane based minimal flow anesthesia for different durations of surgery. Int J Basic Clin Pharmacol 2016;5:2528-33. 